\title{
O USO DO RADAR DE PENETRAÇÃO DO SOLO (GPR) NA CARACTERIZAÇÃO DA ARQUITETURA DEPOSICIONAL DE FEIÇÕES EÓLICAS
}

Israeli Rodrigo Mathias dos Santos ${ }^{1}$, Guilherme Borges Fernandes ${ }^{1}$, Gleverson Guizan Silva1', Universidade Federal Fluminense

Copyright 2016, SBGf - Sociedade Brasileira de Geofísica

Este texto foi preparado para a apresentação no VII Simpósio Brasileiro de Geofísica, Ouro Preto, 25 a 27 de outubro de 2016. Seu conteúdo foi revisado pelo Comitê Técnico do VII SimBGf, mas não necessariamente representa a opinião da SBGf ou de seus associados. É proibida a reprodução total ou parcial deste material para propósitos comerciais sem prévia autorização da SBGf.

\section{Abstract}

This work aims to study aeolian features that are relatively rare on the coast of the state of Rio de Janeiro, and its architecture in the subsurface using the Ground Penetrating Radar (GPR). The study area is in the municipality of Atafona part of the deltaic complex of River Paraiba do Sul in the north coast of the State of Rio de Janeiro.

\section{Introdução}

O Radar de Penetração do Solo (GPR) tem sido amplamente utilizado, pois possibilita a detecção da espessura das unidades deposicionais, forma, orientação e descontinuidades das camadas de maneira nãoinvasiva, representando um importante aliado às informações obtidas por sondagem e trincheiras (NEAL 2004).

$\mathrm{Na}$ aquisição do dado GPR sobre o ambiente eólico espera-se encontrar registros de suas estruturas internas e da arquitetura deposicional e dessa maneira adquirir informações a respeito desse ambiente e suas caracteristacas deposcionais.

A área de estudo está localizada no município de Atafona que faz parte do complexo deltaico do Rio Paraíba do Sul no litoral Norte do Estado do Rio de Janeiro. A aquisição das linhas GPR foi realizada numa planície Quaternária Holocênica no Delta Sul e que tem como caracteristica uma extensa área de feixes arenosos alongados formados pelo acumulo de sedimentos arenosos quaternários marinhos.

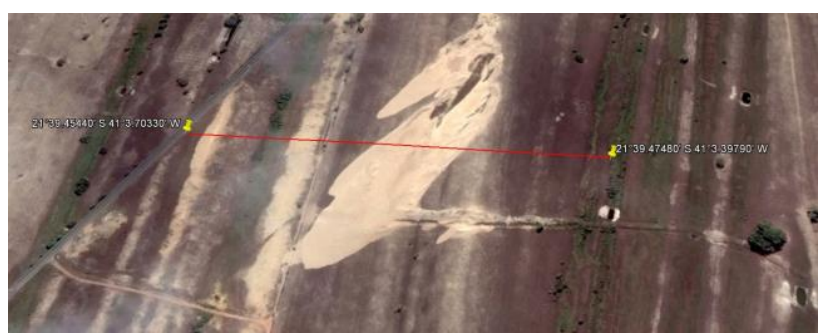

Figura 1 -Detalhe da duna em cristas de praia localizada na seção A da figura 2.

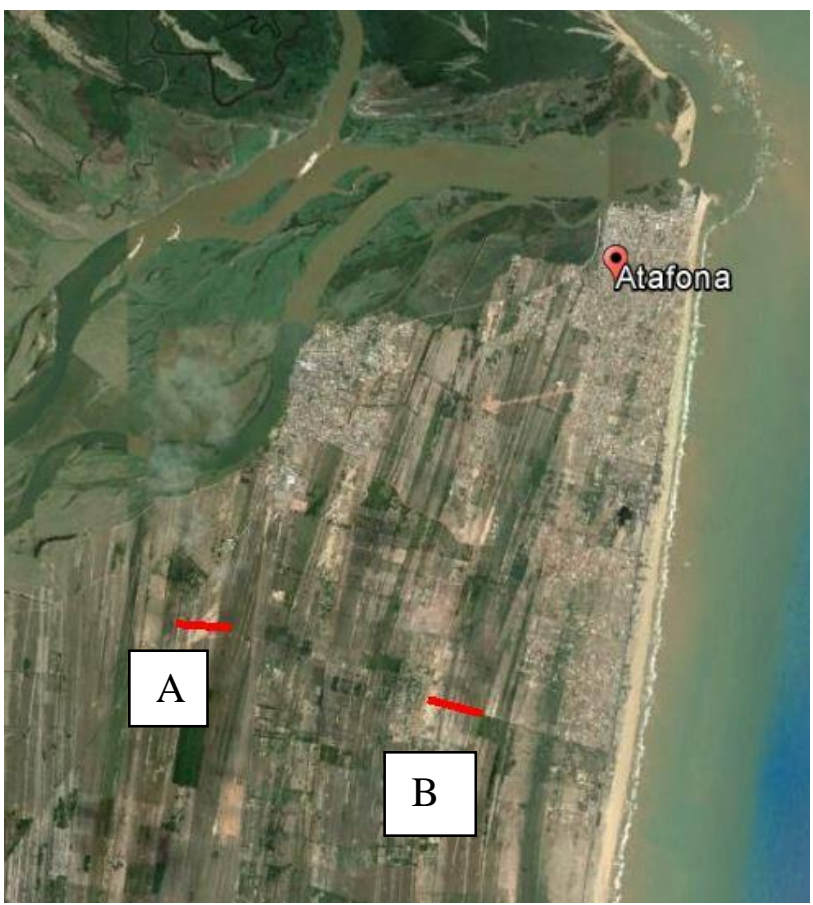

Figura 2 -Área dos levantamento GPR linha A e B

\section{Metodologia/ Problema Investigado}

O procedimento adota três etapas principais: Aquisição, Processamento e Identificação da arquitetura deposicional.

Foi utilizado a antena de $400 \mathrm{MHz}$ e módulo SIR 3000 de fabricação da GSSI, para a aquisição de dados em campo. A antena e rebocada pela área em uma trajetória retilínea enquanto realiza a emissão e recepção de onda eletromagnética.

Os perfis GPR foram adquiridos em modo Commonoffset. Este é o método de aquisição mais utilizado para investigação de arquiteturas sedimentares.

Para o processamento foi utilizado o software RADAN 6.6 da GSSI que se mostrou bem eficiente no processamento das linhas aquisitadas em campo.

Os parametros ambientais utilizados para o processamento foram os de areia seca por se tratar de um ambiente eólico, com velocidade do onda em torno de $0,06 \mathrm{~m} / \mathrm{s}$. Após utilizar a ferramenta Interactive Interpretation podemos verificar que os resultados da 
velocidade da onda ficam bem proximos aos dados de topografia lançados na linha.
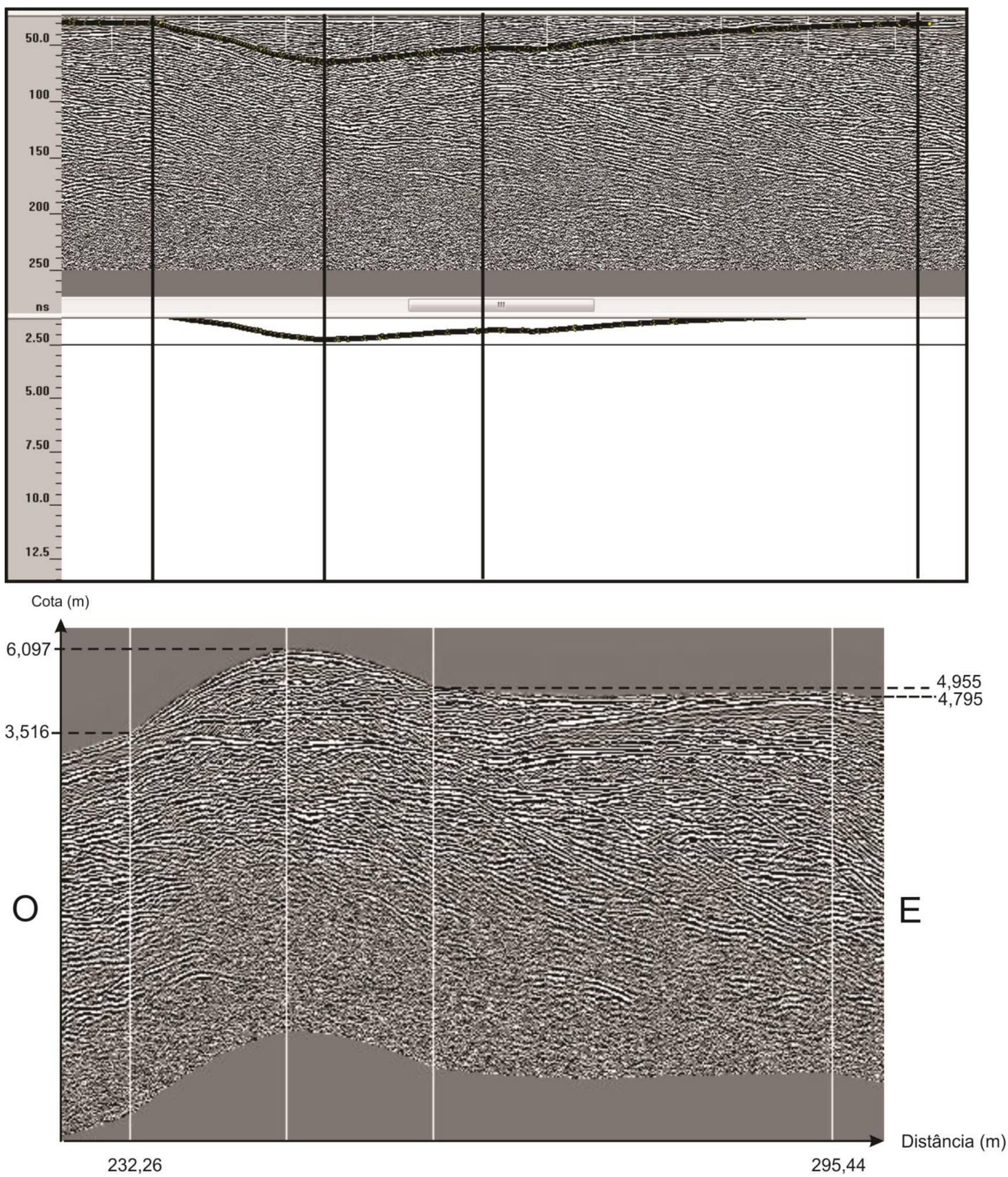

Figura 3-Processamento da linha mostrando a velocidade no processamento e 0 processamento após o acrescimo da topografia. 


\section{Resultados}

Foram observados dois ambientes presentes no radargrama, um praial progradante, em direção ao mar, na parte inferior e na parte superior um ambiente eólico. A parte eólica que foi o objetivo deste trabalho e suas estruturas internas são características deste tipo de ambiente de Duna Frontal.

Outro ponto observado foi a amarração dos dados durante o procesamento no qual podemos observar (figura 3) que tanto a curva de velocidade da onda eletromagnética como a topografia apresentam valores muito proximos de $2,5 \mathrm{~m}$.

\section{Discussão e Conclusões}

A análise da linha GPR indicou uma provavel presença de arquiteturas tipicas de ambientes eólicos, dadas as caracteristicas apresentadas no radargrama, no qual podemos identificar uma estrutura planar tipica de Duna, pela presença de uma superfície delimitadora (bounding surface) e de estratificação cruzada (cross-strata) e compõem a sua estrutura primaria (Pye, Tsoar 2009), o que e tipico de Duna frontal, não foi possivel identificar as estruturas secundarias por se tratar de uma área de inter dunas o que não existe no local.

Podi-se observar um mergulho da parte praial em direção ao mar(Leste) o que indica uma progradação tipica de ambiente deltaico.

\section{Agradecimentos}

Ao Professor Dr. Guilherme Borges Fernandez e toda equipe do Laboratório de Geografia Física, pela oportunidade de realizar esse Trabalho Final I e pela ajuda na busca pelo conhecimento e pratica com o método GPR e ao Professor Dr. Gleverson Guizan Silva pela orientação no decorrer do trabalho.

\section{Referências}

GEOPHYSYCAL SURVEY SYSTEMS, INC. 2009 RADAN Manual. p. $1-215$.

JOL. H. M,. 2009. Ground Penetrating Radar: Theory and Applications. p.5-17/281-294.

KEAREY. P, BROOKS. M, HILL. I, 2009. Geofísica de Exploração. p. $382-387$.

MACHADO. H. C. A ,2014. Mapeamento Geomorfológico da Planicie do Delta do Rio Paraiba do Sul, no Norte Fluminense. p. $8-55$.

NEAL. A,. 2009. Ground-penetrating radar and its use in sedimentology: principles, problems and progress. p. 308 $-320$.

PYE. K, TSOAR. H,. 2009. Aeolian Sand and Sand Dunes. p. $255-292$. 


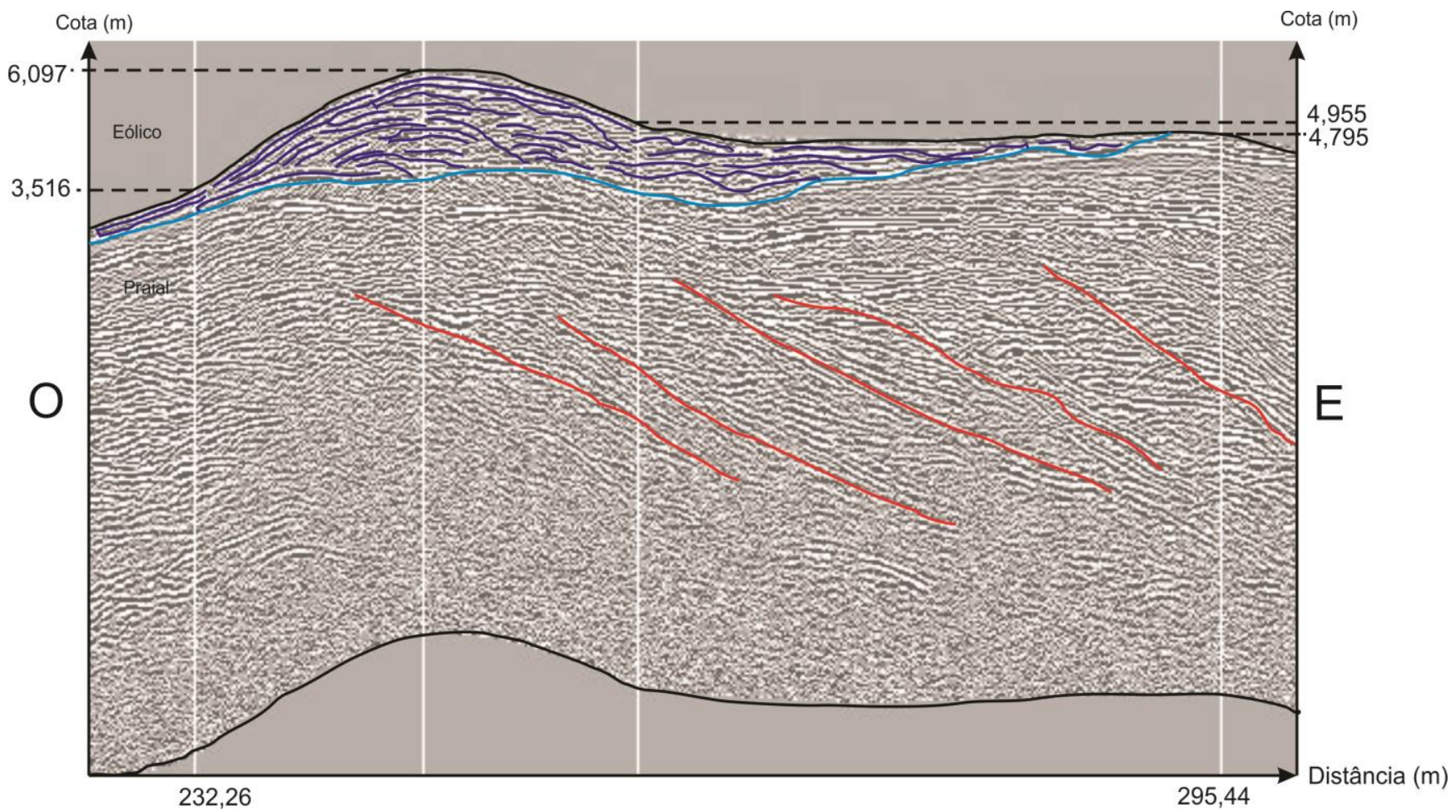

Figura 4-Radargrama processado com dois ambientes e pacote eólico no detalhe. 